\title{
DESARROLLO ENDÓGENO SOSTENIBLE DE REGIONES INTERFRONTERIZAS. LA REGIÓN DE LA GUAJIRA-COLOMBIA Y EL MUNICIPIO LA GUAJIRA- VENEZUELA
}

\section{SUSTAINABLE ENDOGENOUS DEVELOPMENT OF INTER-BORDER REGIONS. THE REGION OF LA GUAJIRA- COLOMBIAAND THE MUNICIPALITY OF LA GUAJIRA- VENEZUELA}

\section{Rafael Espinoza (Universidad del Zulia) ${ }^{1}$}

\section{Resumen:}

Este artículo tiene como objetivo destacar que el desarrollo endógeno sostenible de regiones interfronterizas venezolano-colombianas está determinado por la calidad del sistema institucional y por el alcance del liderazgo regional que sustente la dinámica de los procesos de dicho modelo de desarrollo. Se asume que el desarrollo sostenible en su dimensión económico-social de una región se puede lograr a través de un proceso que esté respaldado por una infraestructura institucional referida al sistema de leyes, reglamentos y normas efectivas que refuerzan la capacidad y aptitud de un lugar para hacer un mejor uso de sus dotaciones de recursos y lograr un mercado mejorado que consiga ser competitivo y emprendedor; y por un liderazgo extendido, proactivo y fuerte.

Palabras clave: liderazgo; instituciones; democracia; endógeno; desarrollo.

Códigos JEL: O, O2, O17, O43.

\begin{abstract}
:
This paper highlights that sustainable endogenous development of cross-border regions is determined by the quality of the institutional system and by the scope of regional leadership on each side of the border, which supports the dynamics of the substantive processes of the development model. It is assumed that sustainable development in its integral dimension of a region can be achieved through a process that is supported by an institutional infrastructure referred to the system of laws, regulations and effective norms that reinforce the capacity and aptitude of a place to make better use of its resources and achieve a dynamic territory that is competitive and enterprising; and for extended, proactive and strong leadership.
\end{abstract}

Key words: leadership, institutions, endogenous growth, regional development.

JEL Codes: O, O2, O17, O43.

\footnotetext{
1 espinozarl@yahoo.com, Universidad del Zulia.

Recibido: 11 de octubre de 2019. Aceptado: 30 de octubre de 2020.
} 


\section{INTRODUCCIÓN}

En una definición amplia del término frontera, es pertinente destacar su contenido sociológico y económico, la cual constituye la concreción de una intensa relación y hasta una interdependencia en las diversas manifestaciones de la vida en sociedad, promovida y ejecutada por poblaciones asentadas a uno y otro lado del límite, entre dos países, hasta un lugar determinado.

Venezuela y Colombia, compartiendo una extensa frontera, tienen hoy el reto de alcanzar el desarrollo de sus regiones de interfrontera; también tienen nuevas herramientas para alcanzarlo. Una de ellas es la integración. A través de ella se busca organizar los territorios fronterizos con medios institucionales con los que se puedan negociar, promover y ejecutar distintas iniciativas de integración que superen la separación que introducen artificialmente los límites políticos; convirtiendo las fronteras en verdaderos espacios de desarrollo e integración.

El desarrollo endógeno sostenible de la interfrontera en su dimensión económica y social requiere la presencia de recursos y medios especiales, por ser una región que se distingue y diferencia de otras. La continuidad territorial de las regiones interfronterizas como las de Venezuela y Colombia hace que de ambos lados se disponga de recursos naturales semejantes, por lo cual se puede considerar la posibilidad de una integración que coadyuve a la utilización equilibrada de los mismos, orientados a un desarrollo sostenible con equidad, lo cual demanda de un sistema institucional que garantice y suministre recursos políticos y sociales para la gobernanza del proceso de desarrollo, y un alto nivel de capital social, que consolide la participación de la mayor cantidad de agentes y actores económicos, académicos, científicos, políticos, sociales, gubernamentales, entre otros. Además, se requiere de estructuras organizacionales de naturaleza reticular que conlleven a la definición y ejecución de la cooperación y la integración.

En ese sentido, es necesario el fomento de la institucionalidad, la cual se refiere a la realización de la estrategia de desarrollo endógeno sostenible en correspondencia al seguimiento de reglas en un marco de derecho, en el que existan sanciones a las conductas en contra de la legalidad de la estrategia. Fomentar las instituciones implica evitar la personalización de la estrategia, a la vez que asegurarse de la existencia de reglas que protejan la pluralidad, multiculturalidad y ecología. También se requiere de estructuras para la integración como son las redes inter-organizacionales interfronterizas.

En correspondencia con lo antes planteado el artículo presenta como objetivos:

- Caracterizar las implicaciones que tiene el sistema institucional para el logro del desarrollo endógeno sostenible de la región interfronteriza la Guajira Venezolana y la Guajira Colombiana.

- Establecer las implicaciones del liderazgo como factor que dinamiza la intervención de los actores estratégicos en la conducción del desarrollo endógeno en la región interfronteriza.

- Establecer la pertinencia y el alcance de las redes interorganizacionales como contexto para gestionar el proceso de integración de los diversos actores para sustentar la gobernanza del desarrollo endógeno sostenible interfronterizo.

La metódica empleada se basa en la utilización de métodos lógicos: el de la abducción inferencial, la deducción, la inducción y el método analítico interpretativo. A partir de ellos, se construyen las reflexiones teóricas y se develan los atributos de las concepciones del proceso de desarrollo endógeno sostenible a partir de un muestreo de definiciones elaboradas por autores 
representativos. También se utilizó el método de la Reflexión Prospectiva para elaborar las inferencias hipotéticas.

Este trabajo se estructura en cinco apartados, incluido éste de carácter introductorio. En el siguiente se analiza la situación de la región objeto de estudio. El apartado tres revisa los distintos argumentos teóricos que fundamentan esta investigación. El cuarto apartado presenta las propuestas de acción. Por último, se exponen brevemente las principales reflexiones que se derivan del estudio realizado.

\section{SITUACIÓN DEL PROBLEMA}

\subsection{Regiones Interfronterizas. La región La Guajira (Colombia) y el municipio Guajira (Venezuela)}

Colombia comparte con Venezuela la segunda frontera terrestre más extensa de América Latina (con cerca de $2.219 \mathrm{~km}$.), ésta se caracteriza por un alto grado de diversidad, de ahí que sea posible identificar cuatro regiones: (1) la región Cesar y La Guajira - Zulia, que queda al extremo norte y donde se presentan las tensiones bilaterales más fuertes por la delimitación terrestre y marítima del territorio; (2) la región Norte de Santander-Táchira, en el área andina de ambos países, que es uno de los puntos con mayor desarrollo e integración socioeconómica de la frontera; (3) la región Arauca-Apure; y (4) la región Vichada y Guainía - Amazonas, que tiene los niveles más bajos de densidad poblacional y los más altos de subdesarrollo de la frontera (PNUD Colombia, 2012).

\begin{tabular}{|c|c|}
\hline $\begin{array}{l}\text { FUGURA 1: DEMARCACIÓN DE LA } \\
\text { FRONTERA VENEZUELA- } \\
\text { COLOMBIA. }\end{array}$ & $\begin{array}{c}\text { FIGURA 2: ÁMBITO } \\
\text { INTERFRONTERIZO EXTREMO } \\
\text { NORTE MUNICIPIO GUAJIRA } \\
\text { (VENEZUELA)-DEPARTAMENTO LA } \\
\text { GUAJIRA (COLOMBIA) }\end{array}$ \\
\hline $\begin{array}{l}\text { FRONTERA TERRESTRE } \\
\text { COLOMBIAY VENEZUELA }\end{array}$ & $\begin{array}{l}\text { Municipio Guajira } \\
\text { Superficie } 2 \text { mil } 369 \mathrm{Km} \\
\text { Población Más de } 65 \mathrm{mil} \\
\text { habitantes (Censo } 2011) \\
\text { Capital Sinamaica } \\
\text { ación norte del Edo. Zula }\end{array}$ \\
\hline $\begin{array}{l}\text { Fuente: Centro de Pensamiento para el Desarrollo } \\
\text { (2018). }\end{array}$ & $\begin{array}{l}\text { Fuente: Comisión para los Derechos Humanos en el } \\
\text { Estado Zulia (Codhez), (2019). }\end{array}$ \\
\hline
\end{tabular}


Considerando el ámbito interfronterizo extremo norte representado en la ilustración, se exponen las características que presentan tanto la zona venezolana como la colombiana:

\section{Zona fronteriza venezolana}

- Dimensión geopolítica:

El Municipio Guajira u oficialmente Municipio Indígena Bolivariano Guajira es uno de los 21 municipios del estado Zulia, en Venezuela. Ubicado al norte del estado, con una superficie de $2.369 \mathrm{~km}^{2}$, y una población de 65.545 habitantes (censo 2011). Su capital es Sinamaica. El municipio está dividido en 4 parroquias. Posee singular importancia en virtud de su posición geográfica y de sus múltiples y complejas relaciones establecidas con Colombia, que le confiere especial interés regional, nacional e internacional. Es relevante la comunicación vial por el Eje Maracaibo-Paraguachón, que conecta con Maicao-Riohacha (Troncal del Caribe) de indudable interés comercial y geopolítico en el entorno andino y caribeño, además las perspectivas de comunicación marinas (Golfo de Venezuela) por ser asiento previsto para la construcción de infraestructura de gran calado en la Isla San Bernardo, municipio Padilla (Puerto Venezuela) y servicio ferroviario y portuario de carbón en Pararú, municipio Paéz.

- Dimensión económica:

Las principales actividades son el comercio internacional, y siendo un municipio fronterizo con Colombia, el contrabando de combustible, víveres y otros productos. El municipio es gran productor de ganado ovino y caprino, y de rubros como tomates, pimentón y melón. Sus habitantes, quienes han desarrollado sus viviendas llamadas palafitos en las aguas de la Laguna de Sinamaica, viven básicamente de la pesca, artesanía, turismo, agricultura y comercio. El municipio la Guajira cuenta con recursos naturales, como salinas, materias primas agrícolas potencialmente industrializables (Cámara de Comercio de la Guajira, 2017 2018).

- Dimensión sociopolítica:

Los pueblos indígenas del Zulia se encuentran en precarias condiciones, sin garantías para sus derechos, en específico el reconocimiento a su identidad sin discriminación, y sobre sus territorios ancestrales y recursos, previstos, entre otros instrumentos internacionales, en la Declaración de las Naciones Unidas sobre los Derechos de los Pueblos Indígenas. En el caso de la Guajira, territorio ancestral de los Añú y Wayuu, las situaciones violatorias a los derechos humanos suelen ser más notorias por tratarse de una zona fronteriza muy poblada y de alto tránsito, con presencia de autoridades militares, policiales y migratorias tanto de Colombia como de Venezuela. También, porque desde 2010 el Estado venezolano decidió reforzar sus posiciones militares desde el puente sobre el Río Limón que demarca el municipio Guajira del Zulia.

\section{Zona fronteriza colombiana:}

- Dimensión geopolítica:

La Guajira es uno de los departamentos con una posición geoestratégica importante, se ubica al norte de Colombia que la enfrenta al Caribe con más de 403 kilómetros de frontera marítima y 249 kilómetros de frontera terrestre con Venezuela y un clima seco que es benigno para muchas actividades comerciales e industriales (PNUD Colombia, 2012).

- Dimensión económica:

La minería, principal actividad económica del Departamento es de enclave, excesivamente especializada, cerrada hacia sí misma y no promueve ni impulsa al resto del Departamento en su crecimiento y desarrollo. 
En relación con la organización de la producción, las empresas que dinamizan el tejido productivo tienen pocos vínculos con el entorno social y económico. El 97,6 por cien de las empresas son de tipo micro, destacándose la precariedad del sector industrial, la debilidad del comercio y la preponderancia de un conjunto de actividades no clasificadas en ningún otro sector, generalmente asociadas con la informalidad. La baja vinculación e inclusión de las empresas de la región limita las posibilidades de iniciar procesos sostenidos de acumulación, generación de empleo e ingresos. Ello significa que al interior de La Guajira se ha consolidado un enclave minero que convive con un entorno en donde priman las prácticas productivas de un conjunto de microempresas sin posibilidades de acumulación en las áreas urbanas y las actividades tradicionales de las comunidades indígenas en el área rural (PNUD Colombia, 2012).

$\mathrm{Su}$ territorio posee importantes yacimientos de sal marina (con capacidad de producir un millón de toneladas), gas (produce entre 300 y 500 MPCD), carbón (reservas establecidas en 3.933,3 millones de toneladas métricas y se exportan 35 millones de toneladas anuales); adicionalmente, la alta iluminación solar que prima en su territorio (277 horas de brillo solar promedio/mes) le permite tener un alto potencial en generación de energía solar (PNUD Colombia, 2012).

- Dimensión sociopolítica:

La Guajira es el Departamento con mayor riqueza étnica, en ella conviven siete etnias indígenas conformadas por el Wayu, con cerca de 500.000 integrantes, los Arahuacos, los Koguis, los Wiwas y los Cancuamos, y recientemente se incorporaron numerosos pertenecientes a las etnia Zenu e Ingas. También residen afrodescendientes y árabes dentro de los cuales se distinguen otros grupos diferenciados, los blancos y los criollos y toda clase de mezclas étnicas.

El Guajiro originario no reconoce fronteras, sus territorios reales abarcan la Guajira Colombiana y la Guajira Venezolana donde comparten sus cementerios, familias y relaciones naturales y comerciales. La frontera política colombo-venezolana se ha convertido en el "Muro de Berlín” para el pueblo Wayu, donde la Guardia Nacional Venezolana los maltrata y la Policía Colombiana los enfrenta, porque sólo ven en los indígenas gente generadora de problemas y delincuentes potenciales y no lo que realmente son, los dueños originales de estos territorios, binacionales por naturaleza (PNUD Colombia, 2012).

La frontera venezolana-colombiana posee una importancia estratégica en el continente por su función como espacio de circulación de intensos e ingentes flujos de mercancías, fuerza de trabajo, bienes tecnológicos e información; así como por los notables procesos de acumulación y reproducción ampliada de capital que se derivan de ese intercambio económico.

Cabe señalar que durante el periodo de crecimiento del Producto Interno en Venezuela (20032009), se instauró una lógica orientada hacia el fortalecimiento de las relaciones binacionales a través de las aduanas localizadas en la frontera compartida, que redundó en un intercambio comercial formal de gran intensidad (cuya balanza favoreció notablemente a Colombia), el cual se expandió hasta aproximadamente ocho mil millones de dólares americanos en el año 2008.

De manera simultánea, en ese periodo se acentuó la intensidad de algunos mecanismos de intercambio comercial informal que han caracterizado históricamente a las regiones fronterizas, y además se configuraron nuevas formas de intercambio ilegal que crearon una racionalidad de acumulación delictiva de capital, por una parte, a través de dispositivos para la captación de la renta venezolana (se instauró todo un aparato comercial y financiero para la transferencia de petrodólares), y por otra parte mediante enormes flujos ilícitos controlados por grupos irregulares. 


\section{DESARROLLO TEORICO-CONCEPTUAL}

\subsection{El Desarrollo endógeno. Una alternativa para la integración y transformación de la interfrontera venezolana-colombiana}

La compleja situación, tanto en la región guajira venezolana, como en la región guajira colombiana, conduce a reflexionar sobre una concepción de desarrollo endógeno que conciba estrategias que transciendan lo específicamente económico y la organización y utilización de las capacidades y potencialidades materiales. La distorsionada cultura sociopolítica que prevalece en el contexto interfronterizo se puede considerar la mayor debilidad y profunda amenaza para una propuesta de desarrollo sostenible. Sin embargo, con una actitud optimista se debe insistir en la reflexión sobre propuestas viables y factibles que se han implementado en territorios deprimidos como los presentados anteriormente, en tal sentido se asume la opción del desarrollo endógeno.

La validación de un proceso de desarrollo endógeno en un territorio implica analizar qué variables están asociadas a cada una de las dimensiones. Por tanto, para Vázquez Barquero (2005) el desarrollo endógeno es el proceso de crecimiento y cambio estructural que utiliza eficientemente los recursos disponibles a través de prácticas innovadoras en la organización de la producción, la participación comunitaria y el fortalecimiento institucional para la utilización del potencial territorial. También considera, que el desarrollo se produce por un proceso de acumulación de capital y de progreso tecnológico; donde la creación y difusión de las innovaciones, la organización flexible de la producción, la generación de economías de aglomeración y de diversidad en las ciudades y el crecimiento del tejido institucional son variables explicativas.

Arocena (2002) señala que el desarrollo endógeno es un proceso en el que los aspectos sociales se integran con los aspectos económicos. Crecimiento económico y distribución de la renta y de la riqueza no son dos procesos paralelos, sino que son parte de un mismo fenómeno, ya que los actores públicos y privados toman las decisiones de inversión no sólo con la finalidad de mejorar la productividad y la competitividad de las empresas, sino también con el fin de resolver los problemas y mejorar el bienestar de la sociedad.

En opinión de Capello et al. (2009), el desarrollo endógeno depende de la constitución de una región, que es un sistema socioeconómico y cultural que define el éxito de la economía local a través de los elementos de las habilidades empresariales, los factores locales de producción (trabajo y capital), gestión de contactos de actores locales, que contribuyen cada vez más a la creación de conocimiento. Los autores también refieren que el desarrollo endógeno puede considerarse que tiene una serie de características distintivas. Estos incluyen la determinación local de las opciones de desarrollo, el control local sobre el proceso de desarrollo y la retención de los beneficios dentro de la localidad

Estas condiciones son importantes ya que varias diferencias territoriales, incluso estadísticamente significativas, no se deben atribuir al uso ineficiente de los factores clásicos de producción, como el capital y el trabajo, sino que son el resultado de problemas regionales más profundos, p. ej. instalaciones geográficas locales, apertura, creatividad, entorno empresarial (Capello et al. 2009).

El paradigma del desarrollo endógeno sostenible implica el aprendizaje y despliegue de códigos y valores humanos, sociales, políticos y económicos, convertidos en un sistema institucional de normas y leyes transferibles a los instrumentos de planificación como son las 
políticas públicas, a partir de las cuales se diseñan las estrategias para orientar el desarrollo que se declaran en los planes, programas y proyectos.

Las referencias teóricas contrastan con la realidad descrita para las dos regiones Guajiras, tanto por autores venezolanos y colombianos, tal y como se expone en la siguiente cita:

"En este centro poblado de Paraguaipoa, la capital de La Guajira venezolana, todo huele a gasolina. Eso es Los Filúos: un enclave de tierra árida a menos de 20 kilómetros de la frontera con Colombia y a dos horas de viaje de las torres de extracción de petróleo del lago de Maracaibo.

Para los 4000 habitantes de Los Filúos, donde el calor extremo y la falta de lluvias hacen casi imposible la agricultura y la ganadería, el contrabando de gasolina es una alternativa de subsistencia. Y también un problema para el futuro" (Codhez, 2019).

\section{FIGURA 3:}

Una fila de taxis junto a la vía principal a la altura de Paraguaipoa, Venezuela. Esta localidad venezolana, el último punto antes de cruzar la frontera con Colombia, es desde hace años un lugar dedicado íntegramente al comercio y flujo de personas entre los dos países.

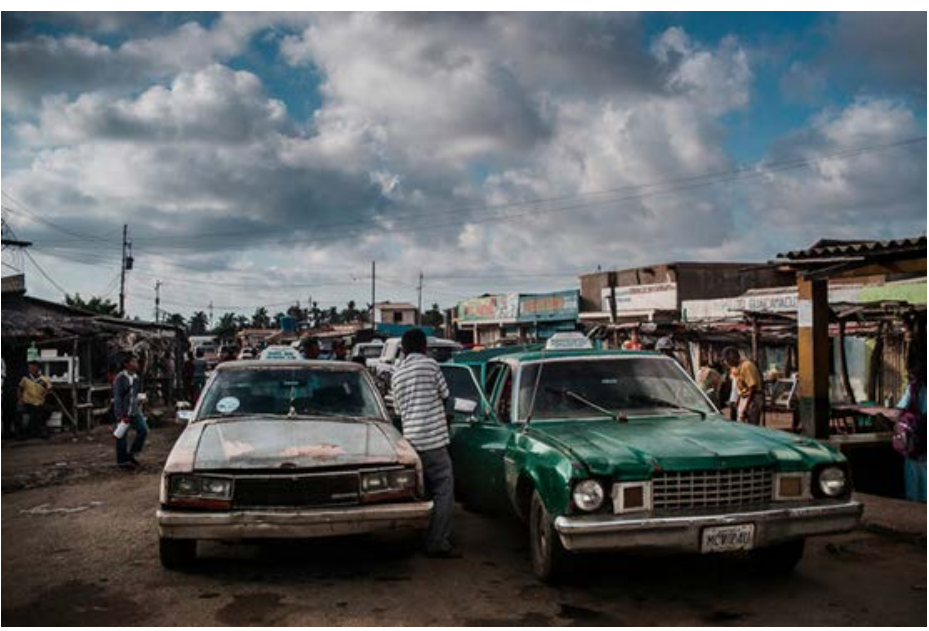

Fuente: Comisión para los Derechos Humanos en el Estado Zulia (Codhez), (2019).

\subsubsection{Inseguridad en la región Inter-La Guajira, obstáculo para el desarrollo}

Las pugnas sociales en Colombia se evidencian como un fenómeno producido por diversas causas que varían de acuerdo a la ciudad y a la región. Desde los noventa, La Guajira hace parte de un consolidado sistema nacional de violencia, ya que la presencia de organizaciones y grupos irregulares que persisten en las actividades ilícitas y en el control de las rentas en la fase del posconflicto, no son individuos anómicos o pobres sin rumbo, sino grupos profesionalizados que muestran recursos, planificación y alternativas para su permanencia.

En la actual fase de violencia e inseguridad en La Guajira todo se encuentra relacionado. A las necesidades de captura de rentas por los grupos ilegales, se ha unido la migración voluntaria de venezolanos que se masifica en el norte del departamento. La población de Riohacha y Maicao se encuentra en alerta generalizada por el grado de inseguridad afectando las actividades económicas, 
lo que se convierte en un obstáculo para el desarrollo local y regional (Centro de Pensamiento para el Desarrollo, 2018).

La sociedad establecida en las regiones interfronterizas carece de empoderamiento y por tanto de participación en el diseño de cualquier proceso conducente al cambio y luego a la transformación, la población mayoritaria que es la indígena, esta marginada de la concepción y ejecución de estrategias, económicas, sociales, educativas entre otras. Existe la consideración de que ellos son un problema. Siguiendo esta línea de análisis e interpretación, se puede señalar que el proceso de desarrollo endógeno sostenible que se conciba debe conducir a una condición de evolución de la sociedad con soporte de una infraestructura institucional que garantice la gobernabilidad y gobernanza de la sociedad regional y local.

En primer lugar, se debe reconocer que la crisis económico-política afecta a los dos países. A pesar de que la economía delictiva, marque una tendencia a generar procesos de acumulación de capital que favorecen a Colombia (sobre la base de una carga histórica de intercambio desigual que se ha instaurado en las relaciones binacionales), lo cierto es que las distorsiones económicasfinancieras de la frontera, afectan los sectores formales de la economía en los dos países, en la medida en que limitan las potencialidades de desarrollo en la región (en lo concreto, las localidades adyacentes a los nodos de intercambio fronterizo actúan como una región económica, más allá de los límites político-administrativos) (Codhez, 2019).

\subsection{Sostenibilidad del desarrollo económico-social}

El desarrollo sostenible conlleva dos significados que deben ser analizados detalladamente por sus implicaciones en la interpretación y valoración que se hace del mismo. El concepto sostenible registra el atributo de autonomía y el atributo de durabilidad, en ese sentido la condición de sostenible se alcanza al tener capacidad para asegurar la posesión de recursos, de medios, tangibles e intangibles que dotan de autosuficiencia a determinados sistemas para diseñar realidades futuras deseables-probables y llevar a cabo procesos direccionados hacia el logro de objetivos fundamentales para la transformación. La condición de sostenible - durable conlleva la doble capacidad de sostenible para existir en el presente y la capacidad de sostenible para modificarse, cambiar, transformarse, desarrollarse y evolucionar.

El proceso de desarrollo igualmente conlleva dos significados, el concepto proceso denota una secuencia de momentos de inicio, continuidad y arribo. En consecuencia, todo proceso implica una dinámica y un tiempo, estos dos factores determinan que el proceso en sí mismo registre el atributo de durabilidad, pero no el de autonomía, lo cual significa que la dinámica del proceso está determinada por factores, condiciones, recursos y medios internos y externos al contexto donde él ocurre.

El concepto desarrollo expresa sentido y dirección, es fuerza que impulsa, que impele para llegar a un Ser o Estado diferente, por tanto el desarrollo se expresa en cambios y transformaciones progresivas de mayor magnitud y complejidad que se suceden en distintos organismos, tal como es la sociedad como sistema humano. Las anteriores conceptualizaciones se presentan para aproximarnos a precisar la naturaleza de la sostenibilidad del proceso de desarrollo económicosocial y la naturaleza del proceso de desarrollo sostenible de regiones deprimidas como son la Guajira Venezolana y la Guajira Colombiana.

La sostenibilidad del proceso de desarrollo económico-social nos lleva a reflexionar respecto al contexto y los factores asociados, un primer aspecto a considerar es el contexto democrático de 
la sociedad a la que corresponde el desarrollo, un segundo aspecto es la infraestructura institucional que resguarda este proceso y, un tercer aspecto, es la cultura de liderazgo extendida en la trama de la sociedad que promueve la gobernanza en la ejecución.

\subsubsection{Contexto democrático}

Asumiendo la premisa que el proceso de desarrollo económico-social es un diseño concebido para fortalecer a la sociedad en democracia, en el entendido que es en esta clase de sistema políticosocial-económico donde se crean y cuidan las condiciones para la intervención libre de todos los ciudadanos y las organizaciones, para conducir las estrategias de desarrollo desde los espacios e instancias donde despliegan sus funciones y actividades. En ese sentido se considera que la sostenibilidad del proceso esta posibilitado significativamente por el sistema de valores, principios y prácticas intrínsecas a una sociedad fundamentalmente democrática. La participación, entre otras acciones, se ejercerá para formular planes y políticas nacionales, regionales y sectoriales, entre los gobiernos y la ciudadanía; definir agendas de desarrollo, elaborar presupuestos, etc.

La finalidad de la participación ciudadana en la planificación pública, es promover la intervención ciudadana en la implementación, vigilancia, control social y evaluación de los diversos planes sectoriales y territoriales que se elaboren en los tres niveles de gobierno. Da lugar a la asunción social de responsabilidades públicas, conjuntamente con el ejercicio de los derechos ciudadanos encaminados al fortalecimiento de la cogestión pública.

La participación ciudadana en el ciclo de las políticas públicas se convierte en un instrumento de control social y político del Estado, por parte de la sociedad, cuando se abre la posibilidad de que la ciudadanía establezca los criterios y parámetros que orientan la acción pública. El control social combina dos dimensiones concurrentes: la transparencia como rendición de cuentas conforme estándares establecidos socialmente en los espacios públicos apropiados, y la responsabilidad de los agentes políticos por los actos practicados en nombre de la sociedad, según los procedimientos legales y patrones éticos vigentes.

Una democracia fuerte siempre fomentará que la sociedad sea activa y abierta, permitiendo el debate público e incluyendo en el propio diseño del gobierno, tanto el acuerdo como el desacuerdo. Y precisamente con la planificación democrática habría que cambiar esa concepción del Estado, sustituyéndola por una constelación de poderes públicos, una retícula en la cual la participación popular vaya haciendo posible el propósito de una democracia avanzada, como dice el preámbulo de la Constitución Venezolana y la Constitución Colombiana.

\subsubsection{Infraestructura institucional}

Las instituciones son cruciales para proporcionar las estructuras de reglas y las organizaciones dentro de las cuales opera una sociedad. North (1990) sostiene que el marco institucional determina la estructura de incentivos de una sociedad. El desempeño económico de una ciudad o región a lo largo del tiempo está fundamentalmente influenciado por la forma en que evolucionan las instituciones, cómo disminuyen la incertidumbre, cómo permiten que las personas tengan acceso a la información y cómo disminuyen las imperfecciones del mercado que aumentan los costos de transacción. Blakely y Bradshaw (2002), al referirse al desarrollo económico regional, consideran la necesidad de contar con arreglos institucionales apropiados para administrar y financiar el proceso de la estrategia de desarrollo regional o local y para garantizar la 
implementación de planes y acciones. Por lo tanto, la capacidad institucional regional para iniciar, llevar a cabo planes y decisiones es fundamental para ese proceso.

Las infraestructuras institucionales pueden proporcionar la estabilidad en decisiones colectivas que de otro modo serían caóticas (Clingermayer y Feiock, 2001). Las decisiones que toman los actores políticos y económicos están moldeadas por las reglas, los valores y creencias incorporados en instrumentos jurídicos, tales como constituciones, los derechos de propiedad y las restricciones informales que, a su vez, configuran el desempeño económico. La naturaleza de esos factores institucionales y el grado en que imponen restricciones o ayudan a facilitar la acción en la búsqueda de oportunidades se consideran condicionantes del proceso de acumulación de capital y, como resultado, del desarrollo económico de ciudades y regiones (Vázquez Barquero, 2005).

$\mathrm{Al}$ mismo tiempo, es importante tener en cuenta que los lugares que tienen instituciones sólidas y capital social extendido, pueden ser más propensos a crear el liderazgo y el espíritu empresarial necesarios para abordar las nuevas condiciones. Sin embargo, se puede argumentar que los lugares de alta calidad institucional y de capital social pueden haber realizado el mejor ajuste al equilibrio (o condiciones de cambio lento), creando así una poderosa capacidad para operar en esa situación, pero tal vez siendo menos aptos para responder a cambios de contexto desplegados rápidamente por incidencia de cambios tecnológicos o fenómenos naturales. En estas situaciones, se argumenta que el liderazgo y el espíritu empresarial son factores que dan dirección y orientación sobre las formas en que otras instituciones, tales como valores, rasgos culturales, constituciones, leyes, regulaciones y prácticas informales cambian para adaptarse. Algunos aspectos clave de las instituciones se relacionan con lo siguiente:

a) Gobierno regional

Junto con los recursos económicos, los factores importantes que crean una ventaja competitiva son la existencia de mecanismos y alianzas regionales, o lo que generalmente se llama gobierno regional. El gobierno regional incorpora la gama de intereses, tanto privados como sectoriales y comunitarios, que participan en la gestión, el servicio y la regulación de la región urbana (O'Neill, y McGuirk, 2002). Por ejemplo, la solidez, estructura y estabilidad de los sectores privados y público en una ciudad o región, y el carácter de las relaciones políticas entre ellos, el grado de división social y la existencia o no de una legislación favorable afectarán a la capacidad de un lugar para responder a amenazas u oportunidades externas. Los antagonismos políticos dentro de un municipio, por ejemplo, podrían ser tan grandes que no es posible una respuesta, negociación o acuerdo coherente entre una amplia gama de grupos políticos y sociales (Parkinson, 1990). Jewson y MacGregor (1997) sugieren que, en el contexto regional, la política importa.

\section{b) Capital social}

Bolton (1992) considera el concepto sentido de lugar al referirse al complejo de características intangibles del lugar que lo hacen atractivo para residentes reales y potenciales e influye en su comportamiento de maneras observables. Él sugiere que el sentido de lugar es una forma de capital social, un activo específico de ubicación que tiene algunas de las características del capital. De Santis y Stough (1999) vinculan el liderazgo y el capital social con las dotaciones de recursos, proponiendo la noción de holgura organizacional que existe en diferentes niveles en diferentes momentos como contribuciones voluntarias a actividades cívicas y que pueden ayudar a crear lo que Bolton (1992) describe como colocar excedente. La región necesita tener el tejido institucional, es decir, una cultura o tradición de coaliciones políticas y colaboración entre los interesados para trabajar y crear una amplia base para el cambio que tenga la amplitud y la integridad para impulsar más allá el interés de ciertos grupos, ya sean privados o públicos 
(Fairholm, 1994). Se considera que el capital social puede reducir la fricción en las transacciones de mercado. Malecki (2011) nota que esto se hace de tres maneras: creando un sistema de reciprocidad generalizada, estableciendo canales de información y proporcionando información y conocimiento ordenado y evaluado; e instituyendo normas y sanciones mediante las cuales se produce el intercambio, con lo que se evitan los arreglos institucionales costosos y legalistas asociados con las transacciones del mercado.

c) Alianzas estratégicas / colaboración comunitaria

Dentro de este concepto está la noción de que el sector privado está compuesto no solo por empresas sino también por organizaciones sin fines de lucro y otras organizaciones sociales o políticas que tienen un interés en la comunidad. Las alianzas o la colaboración entre las partes interesadas permiten a los gobiernos disminuir sus limitaciones financieras y difundir la responsabilidad del éxito o el fracaso (Stimson et al., 2003). Por lo tanto, se debe enfocar en la tendencia de los actores regionales (públicos, privados, inmediatos e individuales) a participar en la resolución de problemas de la región.

d) Relaciones centro-locales

Estas relaciones tienen implicaciones importantes para las responsabilidades de los gobiernos sub-nacionales de cómo se gestiona el desarrollo regional. Los controles rígidos obstaculizan la flexibilidad necesaria para la innovación y el pensamiento creativo (Derr et al., 2002). La descentralización del poder puede permitir a los líderes de la comunidad tomar sus propias decisiones de acuerdo con las necesidades específicas de una región. Es decir, tienen una amplia autoridad o son parte del grupo clave de toma de decisiones (Fainstein, 2000). Se puede decir que el alcance de la acción regional y su acceso a los recursos dependerá de la cantidad de descentralización institucional existente dentro del sistema urbano de una nación (Jessop, 1998).

\subsection{Institucionalidad para el desarrollo endógeno}

La conducción del desarrollo regional endógeno es el resultado de la voluntad de los actores sociales, políticos y económicos para concertar la intervención de manera activa en los procesos de desarrollo que se generan en un territorio organizado. Cuando se analizan los procesos de desarrollo regional, un factor primordial a considerar es el nivel de institucionalidad. El diseño y aplicación de nuevas políticas y estrategias de desarrollo regional suponen, al mismo tiempo, la creación de una nueva institucionalidad regional, capaz de llevar adelante el modelo de desarrollo endógeno considerado.

North (1990) asume que las instituciones son las limitaciones ideadas por el hombre que dan forma a la interacción humana. El cambio institucional, por tanto, conforma el modo en que las sociedades evolucionan a lo largo del tiempo, lo cual es la clave para entender el cambio histórico de las organizaciones. Agrega North que las limitaciones institucionales incluyen aquello que se le prohíbe hacer a los individuos y a las organizaciones, a veces, las condiciones en que a los individuos se les permite hacerse cargo de ciertas actividades. El desempeño económico de una ciudad o región a lo largo del tiempo está influenciado fundamentalmente por la forma en que evolucionan las instituciones, cómo disminuyen la incertidumbre, cómo permiten que las personas tengan acceso a la información y cómo disminuyen las imperfecciones del mercado que aumentan los costos de transacción

North (1990) considera, además, que las instituciones constituyen, por consiguiente, el marco en cuyo interior ocurre la interacción humana. Son un sistema de reglas y procedimientos a través 
de los que se toman decisiones de autoridad y en el marco de las cuales los actores estratégicos resuelven sus conflictos.

Ostrom (2005) señala que para entender las instituciones se necesita saber qué son, cómo y por qué están diseñadas y sostenidas, y qué consecuencias generan en diversos entornos. En términos generales, las instituciones son las prescripciones que las personas utilizan para organizar todas las formas de interacciones repetitivas y estructuradas, incluidas las de familias, vecindarios, mercados, empresas, ligas deportivas, iglesias, asociaciones privadas y gobiernos a todas las escalas. Las personas que interactúan dentro de situaciones estructuradas con reglas enfrentan opciones con respecto a las acciones y estrategias que toman, lo que lleva a consecuencias para ellos y para los demás.

El trabajo de Ostrom (2005) ha resaltado la importancia de las soluciones institucionales endógenamente emergentes para una variedad de problemas de coordinación, así como el potencial de resultados no deseados cuando las autoridades políticas construyen artificialmente soluciones institucionales a estos problemas en el contexto del desarrollo económico que posteriormente reorienta su concepción, concibiendo a las instituciones como conceptos compartidos utilizados por los seres humanos en situaciones repetitivas organizadas por reglas, normas y estrategias (Ostrom, 2007).

En una particular perspectiva, Aoki (2007) establece un marco de referencia microeconómico basado en la teoría de juegos: una institución es un sistema autosostenido de creencias compartidas sobre cómo se juega el juego. Su esencia es una representación condensada de las características sobresalientes e invariables de una trayectoria de equilibrio, que casi todos los agentes consideran relevantes para sus decisiones estratégicas. Como tal, rige las interacciones estratégicas de los agentes de una manera auto-impuesta, y a su vez, es reproducida por sus elecciones en un ambiente cambiante.

Aoki (2007) propone una definición relativamente cercana al atribuir cinco propiedades a la institución: a) es una creación endógena que perdura en tanto que ningún agente se interese en modificar unilateralmente su comportamiento; b) es un medio para reducir la incertidumbre; c) las reglas institucionales son robustas en el tiempo; d) existe una diversidad de instituciones ya que ellas no son contingentes y, e) es una creencia compartida.

En términos de teoría de juegos, Aoki (2007) no define una institución como "las reglas del juego" sino "como el equilibrio de un juego" que es el resultado de las interacciones de los agentes. Pero debe preverse una visión menos individualista del poder. Si el poder económico es una fuente de cambio, el poder político proporciona la fuente tanto de la selección de propósitos y reglas públicas como de la regulación de los procesos y prácticas económicas. Sin embargo, los propósitos públicos afectan los intereses y valores económicos individuales.

Las referencias anteriores exponen el significado y valor de la institucionalidad a los fines de orientar y lograr el equilibrio de los diversos procesos conducidos por las personas en sus diversas interacciones humanas tales como las económicas y sociales. En correspondencia a lo señalado y directamente relacionado con el rol de la institucionalidad para la materialización del desarrollo endógeno, Vázquez Barquero (2005) afirma que las economías funcionan siguiendo normas e instituciones específicas, formales e informales, que se han ido creando a medida que el sistema productivo, la cultura y la propia sociedad se desarrollaban y agrega (Vázquez Barquero, 2007) que el desarrollo económico toma fuerza en aquellos territorios que tienen un sistema institucional evolucionado, complejo y flexible. Su relevancia estratégica reside en que el desarrollo institucional permite reducir los costes de negociación y producción, aumenta la confianza entre 
los actores económicos, estimula la capacidad empresarial, propicia el fortalecimiento de las redes y la cooperación entre los actores y estimula los mecanismos de aprendizaje y de interacción.

\subsection{Liderazgo del desarrollo regional basado en la estructura reticular}

Hofstede (1993) plantea que el liderazgo es un proceso de interacción social y organizacional en un contexto reticular de gran complejidad que no está aislado y tiene lugar dentro de otros procesos en la sociedad. El liderazgo implica la capacidad de realizar múltiples roles y comportamientos que circunscriben la variedad requerida implicada por los contextos sociales, organizacionales o ambientales (Denison et al., 1995).

De acuerdo a Rojas (2012), el liderazgo es propio de una comunidad, de distintas personas según sus competencias y momentos. Así, el liderazgo se entiende como distribuido, pues no es algo hecho por el líder con o sobre otras personas, ni siquiera es un conjunto de acciones individuales a través de las cuales las personas contribuyen a las metas grupales, sino que es una actividad colectivamente coordinada -consciente o inconscientemente- que opera en las interacciones sociales, a través de la cual se construye y se fortalece el conocimiento y la cultura en la organización y la comunidad respecto a la consecución de metas y objetivos.

En el contexto del desarrollo endógeno regional por su naturaleza compleja, el liderazgo adquiere matices diferenciales ya que no se trata de la idea tradicional del líder y los seguidores, sino de la emergencia desde las bases de líderes que representan a la comunidad; es este perfil lo que hace que el líder sea un actor económico, social, cultural, político, comprometido con las necesidades y demandas que expresan la mayoría de los integrantes de la comunidad, así como también dispuesto a reconocer y asumir las soluciones que se conciben democráticamente por la mayoría; de no ser así cuando sus actuaciones ya no recogen los intereses colectivos, definitivamente la comunidad deja de legitimarlo y se anula (Aguilar, 2001).

La realidad que se registra de pobreza, marginalidad, inseguridad y economías de subsistencia en las regiones interfronterizas venezolana y colombiana, evidencian la presencia de un gobierno conducido por un líder transaccional, el cual hace uso del poder como medio para negociar los intercambios de recursos y medios institucionales y financieros entre el gobierno y los diversos actores de la comunidad y no así para el fortalecimiento de la democracia participativa mediante el diseño y ejecución de estrategias dirigidas a progresar en el desarrollo endógeno. Tradicionalmente el gobernante regional ha asumido la lógica de la hegemonía partidista y personal, por encima de la democracia política-social participativa, haciendo que se minimicen las capacidades de la comunidad para producir resultados mediante la utilización de los recursos endógenos de que disponen.

En Venezuela y Colombia, la desconfianza de los ciudadanos hacia los gobernantes se asocia en gran medida con la corrupción y la poca transparencia en el ejercicio del gobierno, que han sido tradiciones del sistema político. Este hecho lleva a reflexionar sobre la necesidad de asumir de manera estratégica la emergencia del liderazgo colectivo para la formulación de un proceso de construcción de cultura institucional desde la comunidad, que lleve a la formulación de una agenda de gobernanza que genere demandas a las estructuras de gobierno.

\subsubsection{El liderazgo en el contexto regional}

El liderazgo siempre debe ser entendido contextualmente, ocurriendo dentro de una configuración regional del poder, autoridad y legitimidad, moldeada por la historia, instituciones, 
objetivos y cultura política. El liderazgo regularmente implica forjar coaliciones formales o informales, verticales u horizontales, de líderes y élites, en orden de resolver los permanentes problemas de acción colectiva, que definen en gran medida los retos del crecimiento y el desarrollo (Williner y Pérez, 2015).

Señala Sotarauta (2016) que existe un consenso emergente que dice que el liderazgo es la pieza que falta en el rompecabezas del desarrollo local y regional. En este contexto, el liderazgo es una forma oculta de agencia, a la sombra de formas visibles de influencia como estructuras e instituciones formales, así como programas y planes de desarrollo.

En el nivel más general, se reconoce que el liderazgo efectivo es uno de los factores que explican cómo y por qué algunas regiones pueden adaptarse y explotar las oportunidades que brindan las complejas y rápidamente cambiantes circunstancias sociales y económicas y también pueden explicar en parte por qué algunos lugares están mejor capacitados que otros para minimizar la interrupción que trae el cambio. El liderazgo efectivo es parte de la historia del desarrollo local y regional (Collingea et al., 2010).

El liderazgo en el contexto del desarrollo económico regional, puede considerarse como la capacidad de crear mecanismos y alianzas estables y duraderas que promuevan la regeneración económica e identifique una gama de habilidades a nivel micro y recursos a nivel macro que pueden generar esa capacidad (Parkinson, 1990). El liderazgo es la expresión de una acción colectiva. Por lo tanto, en el desarrollo económico regional, el liderazgo generalmente se asume como una acción colaborativa (Heenan y Bennis, 1999). En correspondencia con las definiciones anteriores se puede considerar al liderazgo como la tendencia de la comunidad a cooperar entre sectores para mejorar el rendimiento económico o el entorno económico de su región.

Es importante destacar, siguiendo a Bass y Riggio (2006), que el liderazgo localizado en el contexto regional implica transformación, pero el mismo puede ser inhibido por aquellos que tienen autoridad formal. El desarrollo de algunas regiones en América Latina se encuentra obstaculizado por las élites que actúan como freno al desarrollo regional porque priorizan su capacidad para mantener su influencia local. Tal es el caso de lo que ocurre en la región interfronteriza venezolanacolombiana, donde el comercio ilegal de gasolina y otros bienes, con la anuencia de actores gubernamentales del municipio la Guajira Venezolana y la Guajira Colombiana se ha convertido en una práctica de la actividad económica pública. El rechazo por algunos sectores sociales reconocidos de tal situación, implica riesgos potencialmente perjudiciales para los líderes que impulsan o facilitan el cambio, pero, como señala Sotarauta (2016), los individuos transformadores también pueden incluir actores sin autoridad formal que derivan su influencia de su capacidad para persuadir a otros.

El desempeño del liderazgo es decisivo para prevenir bloqueos y para tratar de encontrar nuevos caminos para salir de situaciones de bloqueo (Beer, et al., 2014). En este estudio, estamos particularmente considerando los efectos de bloqueo que proceden dentro de la propia comunidad (bloqueos endógenos).

De acuerdo a Maskell y Malmberg (1999), se debe prestar especial atención a todos los factores y fuerzas implicadas en el desarrollo regional para evitar los bloqueos causados por la trayectoria de la dependencia regional y para liberarlos si han ocurrido.

Se han identificado tres efectos de enclavamiento endógeno que influyen en las acciones de cambio a nivel de la comunidad. Primero, los efectos de bloqueo estructural son relacionados con los procesos que están fuera del control de comunidades individuales. Estos incluyen factores estructurales que dan forma a las sociedades, tales como códigos morales, sociales, tradiciones, 
religión; la orientación política de una región (Wilson, 2013). También son importantes los factores estructurales y físicos, como la integración de las comunidades en las redes de servicios públicos, o la ubicación geográfica de una comunidad con limitaciones y oportunidades para el desarrollo económico. Los códigos morales definen particularmente la base filosófica sobre la cual se lleva a cabo la acción comunitaria, y encuentran expresión a través de tradiciones y ritos específicos que generalmente están influenciados por factores más allá del nivel comunitario.

En segundo lugar, los efectos de bloqueo económico están directamente asociados con el capital económico y están particularmente con las dependencias de los medios relacionados con la pobreza a nivel comunitario como un componente clave de las comunidades vulnerables (Chaskin, 2008). La falta de recursos financieros significa que estas comunidades tienen pocas oportunidades de abordar los problemas de transformación económica, ya sea en forma de estrategias mejoradas de gestión sostenible socio-económica o por la incapacidad de dedicar suficiente tiempo y esfuerzo más allá de las necesidades inmediatas de supervivencia.

En tercer lugar, los efectos de bloqueo psicosocial son endógenos a nivel comunitario. Burton et al., (2008) sugieren que muchos grupos de partes interesadas dentro de las comunidades a menudo son reacios a romper las dependencias y cambiar hacia trayectorias más convenientes debido al conservadurismo psicológico, también denominado resistencia cultural. Aunque adoptar nuevas estrategias para solucionar los problemas de la comunidad puede ser relativamente fácil, desarrollar una nueva actitud y cambiar la cultura de un modo mental a otro es difícil (Wilson, 2013). Las comunidades fronterizas, son un ejemplo apropiado de conservadurismo psicológico debido a su fuerte arraigo con los estilos de vida interfronterizos y las dependencias del gobierno central, lo que significa que a menudo son resistentes al cambio. En correspondencia con lo anterior se puede considerar que los ciclos viciosos de conservadurismo psicológico pueden estar en funcionamiento precisamente cuando las comunidades afectadas por la corrupción, el desempleo, la marginalidad, pueden necesitar más liderazgo y mentalidad abierta.

\subsubsection{Redes para el liderazgo colectivo}

Los cambios en los procesos sociales, económicos y políticos están asociados, al desempeño de los liderazgos respectivos y en las redes de actores, éstos han sido factores clave para movilizar el apoyo de los agentes involucrados en sus diferentes sistemas de acción y definir las estrategias de las redes, entre otras acciones.

La definición básica de liderazgo en red establece que es una acción que dirige todas las operaciones y recursos de la red hacia la dirección deseada (Kamensky, 2000). La gestión por interacción es parte del liderazgo de la red. Kickert et al. (1997) señalaron que para obtener resultados, la gestión de la red depende de la capacidad de los actores para demostrar liderazgo. Sotarauta (2016) identifica las características esenciales del liderazgo de la red. Según él, el liderazgo debe actuar como mediador en la interacción entre diferentes actores. Además, el liderazgo de la red debe dirigir las actividades para buscar objetivos comunes. Agrega el autor que las características esenciales para el liderazgo de la red son la negociación, la comunicación, la persuasión y las habilidades visionarias.

No solo es importante crear un consenso para un curso de acción conjunto entre representantes de organizaciones, sino también establecer el apoyo para estas ideas dentro de la comunidad. Por lo tanto, el éxito y la efectividad de un proyecto de desarrollo endógeno en red dependen en gran medida de la calidad de su liderazgo. Los representantes deben asumir riesgos al 
aceptar nuevas ideas y estar preparados para sustentarlos y de ser necesario defenderlos en su organización y comunidad.

El liderazgo colectivo se produce cuando las personas se integran y movilizan recursos y medios económicos, institucionales, humanos, organizacionales, culturales y tecnológicos de maneras que mejoran sus comunidades para el bien común. Es un enfoque reticular, intrínsecamente inclusivo porque indica a las personas que crucen las fronteras de diversas limitaciones sociales, políticas y culturales, mientras se comprometen con la acción conjunta, la responsabilidad compartida y la responsabilidad mutua y el aprendizaje bidireccional.

En las redes de actores sociales, económicos y políticos se encuentran liderazgos basados en formas tradicionales de dominación, pero también los hay potencialmente democratizantes que eventualmente podrían contribuir, de una manera intencionada, a la formación de actitudes proactivas en la población. Esto refuerza la convicción de que la constante contradicción entre actitudes mentales, lógicas de actores y organismos antiguos y modernos, que se expresa en el entramado institucional, puede ser administrada a través de las nuevas formas de relación sociedadgobierno (Natera Peral, 2005). Algunas experiencias de las redes de organizaciones civiles, muestran su capacidad para fungir como transmisoras y difusoras de actitudes, percepciones y disposiciones de los liderazgos más proclives al cambio y la institucionalidad.

Es precisamente a través de las redes interorganizacionales que se configuran en los procesos políticos, económicos y sociales, que ocurre la conexión entre los diversos actores económicos y sociales y los organismos públicos para llegar a la cooperación, pero también al conflicto y al disenso. Consideramos que la expresión del disenso puede ser una forma de cooperación que administrada eficazmente puede evitar el conflicto y lograr la inclusión de intereses previamente excluidos.

Es preciso enfatizar que la importancia de las redes como conectoras entre los diferentes actores sociales y los gobiernos y como vías de expresión de la cooperación, requiere la existencia de al menos un mínimo de confianza del conjunto de los actores sociales en los gobiernos. Cooperación y confianza son elementos en constante reformulación y en ellos los liderazgos son un factor clave.

Al analizar las trayectorias políticas de la élite dirigente de organizaciones civiles y de gobierno y su relación con los procesos de cambio político en Venezuela y Colombia, se encuentra que el cambio institucional, asociado a la democratización del poder, y las transformaciones en los repertorios de acción colectiva de los actores reconocidos están relativamente ausentes.

\section{PROPUESTA DE ACCIÓN}

Una red inter-organizacional se puede definir como una estructura de actores y agentes, las cuales son organizaciones, que están unidas por uno o más tipos específicos de interdependencia y codependencia, tales como valores, visiones, ideas; intercambio de medios y recursos; producción de conocimiento, producción de bienes, prestación de servicios, relaciones académicas, relaciones de negocios, relaciones políticas, que posibilitan la co-evolución del sistema inter-organizacional.

En una concepción valorativa, Morales Zepeda (2007) señala que la red inter-organizacional es un concepto evaluador de los procesos de desarrollo del tejido social en su relación con su desarrollo político, económico y sociocultural, aspectos que son indivisibles de las condiciones de evolución del espacio geográfico. Igualmente, Morales Zepeda (2007) expresa que la interacción que se establece en cada actividad productiva, en su propio escenario de desarrollo, involucra a un 
conjunto de dependencias gubernamentales, centros de investigación y productores, cuya interacción son la base en la que evolucionan las redes inter-organizacionales, concepto que permite estudiar las condiciones endógenas en las que se genera la vinculación entre los distintos factores que intervienen en el desarrollo regional: territorio, cultura, trabajo, capital, entre otros.

La estructura reticular favorece la expansión de las relaciones horizontales sin intervenir en aspectos característicos y propios de los ámbitos, niveles y sectores existentes en el entorno de la región interfronteriza. Básicamente, el ordenamiento de los agentes gubernamentales, económicos, políticos, culturales y sociales sería en razón de promover la coherencia en decisiones de incidencia de los actores estratégicos en el contexto territorial e incrementar los niveles de confianza interorganizacional para las relaciones que puedan establecerse.

En correspondencia con lo antes expuesto se puede referir que en el contexto del territorio interfronterizo se registra la presencia de algunas redes inter-organizacionales mayormente informales constituidas por organizaciones de diversa naturaleza, las cuales llevan a cabo procesos complementarios orientados al logro de objetivos para el establecimiento del desarrollo integral y sostenido.

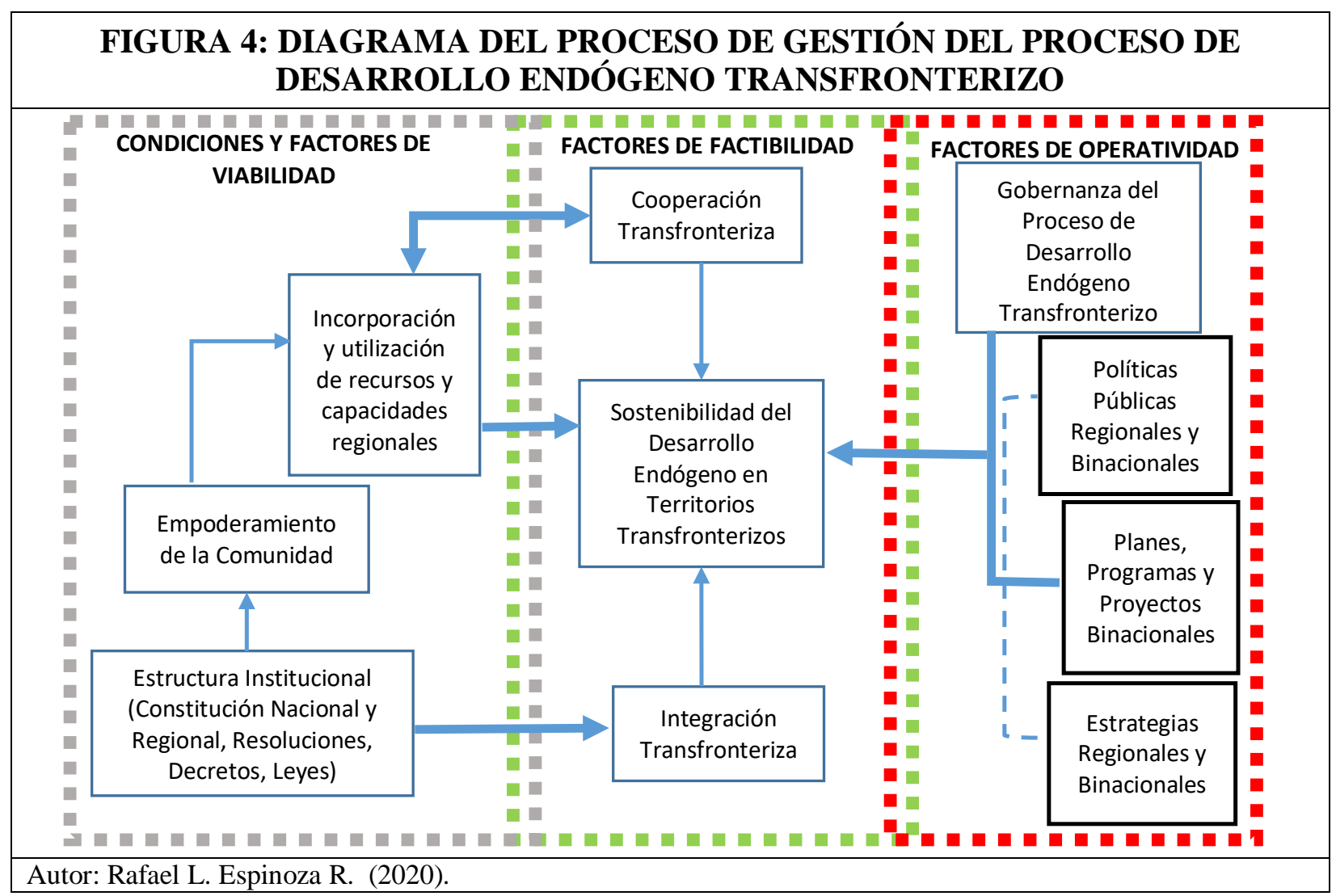

La proposición de estructuras reticulares que conlleven a la gestión del desarrollo endógeno sostenible, implica la identificación y aceptación de lineamientos de naturaleza jurídica, política, económica, social, cultural, y tecno-científica, acerca de la concepción de la sostenibilidad de estrategias, políticas públicas y estructuras, para el desarrollo integral, que se pretenden validar como pertinentes para el territorio regional, asumiendo lo siguiente: 
- El desarrollo de las regiones de frontera depende de la capacidad de integrar las iniciativas empresariales en un ambiente que facilite su concreción y su crecimiento: infraestructuras productivas, servicios a las empresas; instrumentos financieros específicos; marketing territorial para atraer otros recursos externos, cuya presencia conjunta garantice el pleno uso de las potencialidades locales.

- El territorio interfronterizo debe disponer de instrumentos adecuados para la aplicación de políticas y de estrategias de desarrollo, consistentes en estructuras de servicios socioeconómicos territoriales: agencias regionales e interfronterizas para el desarrollo; sistemas de información territorial; parques científicos y tecnológicos, incubadoras de empresas y zonas empresariales.

- Una concepción de gobernanza interfronteriza que trasciende el sentido de la exclusiva acción del gobierno, e involucra de manera directa a los sistemas sociales, especialmente en los niveles regionales de frontera.

- Una noción de gobernanza que se reconoce asociada a los procesos colectivos de toma de decisiones, de negociación de prioridades, de distribución equitativa de la acción de gobierno y a los valores que garantizan la institucionalidad democrática.

- Las fortalezas provenientes de la institucionalidad de cada territorio y sus dones más relevantes (incluida la cultura, el saber local y el conocimiento territorial), como recursos disponibles para el desarrollo regional.

- La cohesión y los acuerdos inter-organizacionales mediante consensos para promover la integración de las regiones de frontera venezolana-colombiana hacia los objetivos de bienestar que incentivan la participación y el compromiso de los gobiernos regionales para apoyar estrategias de innovación y emprendimiento con la participación de los actores económicos.

- El desarrollo del territorio regional exige promover redes socio-productivas. Es necesario enfatizar en líneas productivas homogéneas como cadenas de valor territorial, con competencias de autoabastecimiento y de reproducción social.

El enfoque de redes, permite reflexionar acerca del alcance y las trayectorias derivadas de la articulación de fuerzas (asociadas a las relaciones con el poder, la producción, el conocimiento y la participación) que apoyen o inhiban en mayor o menor medida, la dinámica territorial de la región interfronteriza, como producto de los acuerdos locales que se establezcan entre el conjunto de organizaciones públicas y privadas involucradas con la propuesta de un diseño operativo para la gestión del desarrollo sostenible. 


\section{FIGURA 5: RED DE INTEGRACIÓN SOCIO-INSTITUCIONAL ENTRE ORGANIZACIONES EN REGIÓN DE FRONTERAS VENEZOLANA-COLOMBIANA}

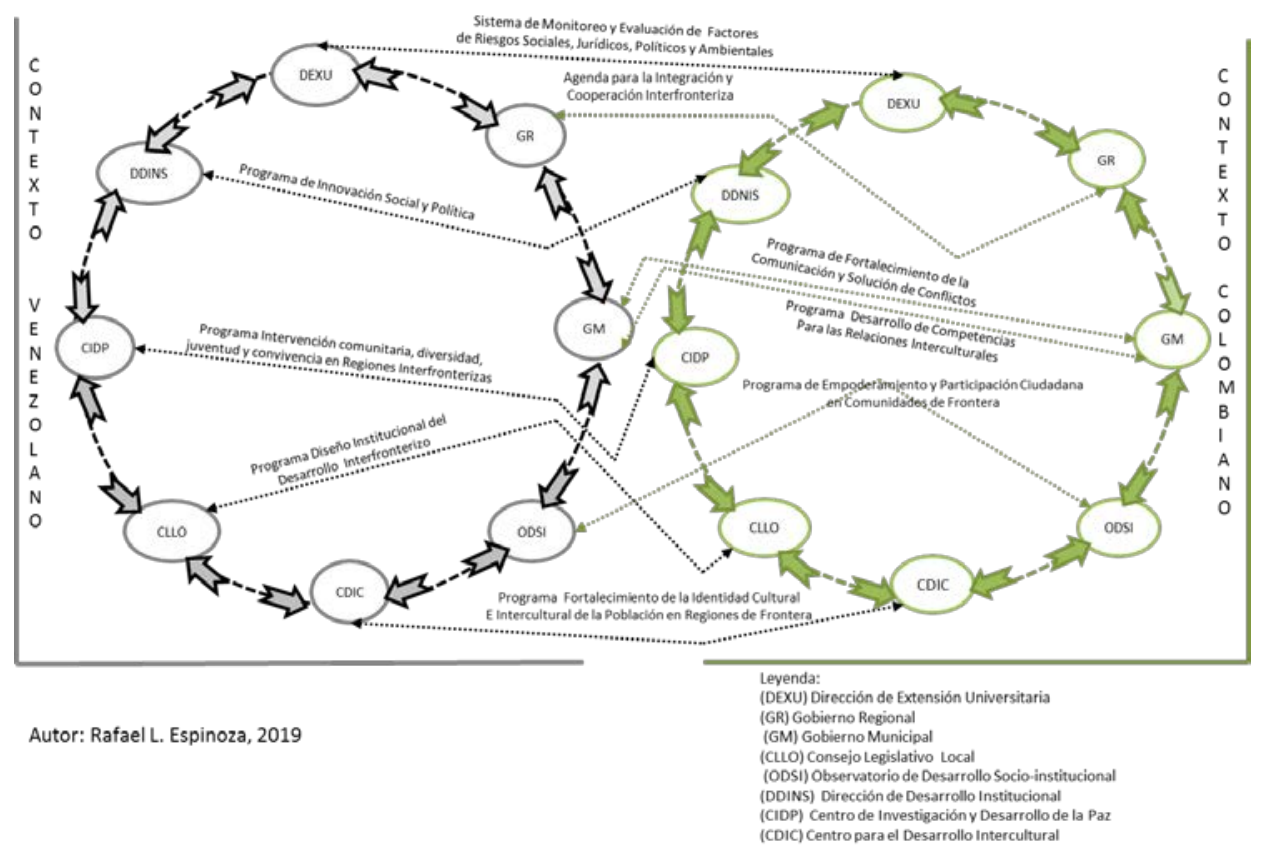

\section{FIGURA 6: RED DE INTEGRACIÓN DE GOBERNANZA DEL DESARROLLO ENTRE ORGANIZACIONES EN REGIÓN DE FRONTERAS VENEZOLANA- COLOMBIANA}

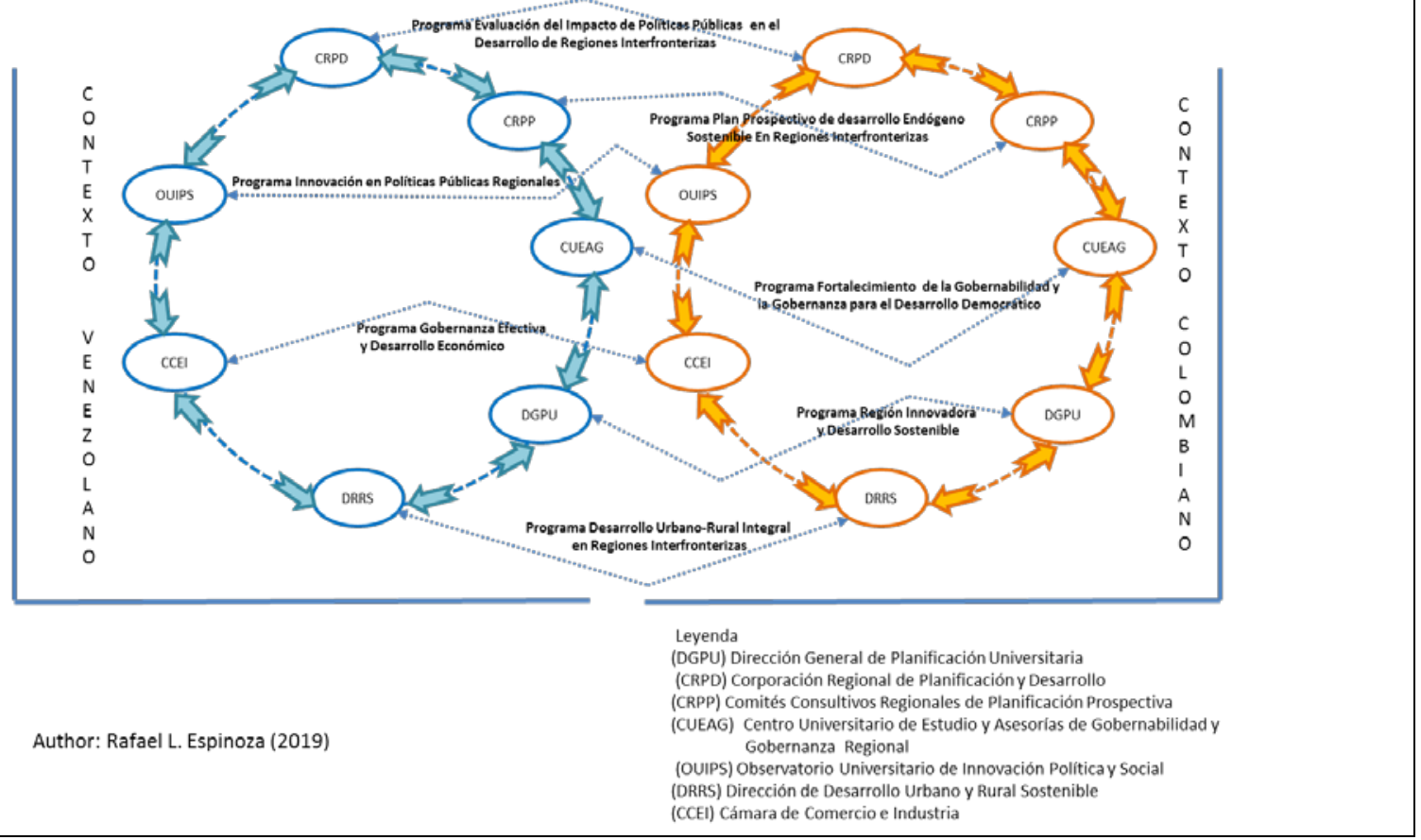


La situación crítica en los municipios de estudio, con un tejido social desestructurado, demanda la concepción de acciones iniciales indispensables que conduzcan hacia la instalación progresiva en el mediano plazo del desarrollo a ambos lados de la frontera. Tal fin requiere una arquitectura de cultura inter-organizacional, noción que conlleva implícitamente la idea de una red compleja de relaciones entre quienes la conforman, y que involucra:

- Una acción de gobierno en el territorio regional, ya no ejercida exclusivamente por el Estado, sino también con la participación de todo el entramado social, evidenciándose un claro reconocimiento de la interdependencia entre el Estado y la Sociedad Civil.

- El reconocimiento y acción de gobernanza endógena del desarrollo que solo será posible en el marco de un territorio socialmente organizado, con capacidades para generar entre sus habitantes sinergias que contribuyan al abordaje y la resolución de problemas comunes en la sociedad, lo cual privilegia el bienestar colectivo.

La consideración de las redes como contexto para gestionar la gobernanza del desarrollo endógeno se sustenta en la participación amplia de las organizaciones de la sociedad civil, así como de los representantes de los gobiernos regionales. La perspectiva territorial del desarrollo endógeno sostenible permite la formulación de una propuesta centrada en las personas, basada en los puntos de interacción entre los sistemas socioculturales y los sistemas ambientales. Al mismo tiempo, incluye la integración productiva y el aprovechamiento de los recursos productivos para viabilizar la cooperación y corresponsabilidad de diversos actores sociales.

Es importante resaltar que el enfoque plantea dos grandes propósitos:

a) La cohesión social, es decir, la construcción de sociedades fundamentadas en la equidad, respeto a la diversidad, solidaridad, justicia social y el sentido de pertenencia; y,

b) La cohesión territorial, como expresión de espacios, recursos, sociedades e instituciones que componen instancias del Estado integradas cultural, política, económica y socialmente. La construcción de la cohesión social sobre la base de la cohesión territorial le confiere al desarrollo regional una orientación más pragmática y apegada a la realidad de los procesos económicos, sociales, culturales, políticos y ambientales que rigen el destino de las naciones (Rodríguez Cohard, 2009).

En la práctica, los propósitos de cohesión social y cohesión territorial se manifiestan en la forma que los socios estratégicos y actores sociales desempeñan un papel determinante en la puesta en marcha de políticas de desarrollo regional sostenible. La inclusión de esos socios y actores sociales implica construir prácticas solidarias (altruismo recíproco) y fomentar la articulación entre los sectores de progreso y los actores sociales marginados.

Las concepciones teóricas de la gobernanza, como estructura de relaciones de decisión, son cada vez más complejas, porque además de involucrar a actores de los diferentes sectores: público, privado y gubernamental, con frecuencia lo hacen con interdependencias a distinto nivel. La interdependencia entre los actores es inherente al concepto de gobernanza. Esta se define como un modelo de entendimiento y toma de decisiones, estrategias y políticas, que vincula a actores formales e informales, en una nueva forma de hacer las cosas, sostenible y sustentable, que coordina y comunica entre los actores involucrados y permite mejorar el control y la transparencia de la gestión pública.

En la anterior definición se da la presencia de un contexto de interacción, de integración para la declaración y ejecución de alianzas entre actores afectados por necesidades y poseedores de recursos para generar soluciones. Por tanto, se presume de una forma de sistema político que 
promueve la institucionalización de la acción colectiva de los ciudadanos para generar recursos y tomar decisiones para satisfacer necesidades. En este sentido diseñar el modelo de desarrollo económico-social pasa por la presencia de una consolidada gobernanza regional, es decir empoderamiento social, democratización del poder.

\section{CONSIDERACIONES FINALES}

La proposición de estrategias que incidan, en el menor tiempo posible, en la generación y dinamización de cambios socio-productivos en el territorio interfronterizo venezolano-colombiano, exige en el marco de una Hoja de Ruta (HR), la previa identificación y aceptación de prioridades para la endogeneidad del desarrollo sostenible que se aspira alcanzar con un compromiso estratégico entre los gobiernos regionales (La Guajira-Venezuela y La Guajira Colombiana) y que se detallan a continuación:

Prioridad 1: Diseñar el marco regulatorio e institucional para asegurar un entorno favorable para el trabajo de las organizaciones de la sociedad civil en el territorio transfronterizo.

Prioridad 2: Fortalecer las capacidades de las organizaciones de la sociedad civil regional para desempeñar con más eficacia su papel de actores del desarrollo endógeno regional y transfronterizo.

Prioridad 3: Fomentar la participación significativa y estructurada de las organizaciones de la sociedad civil en las políticas regionales de alcance binacional, en la programación de la integración y la cooperación en los procesos internacionales.

Prioridad 4: Alcanzar acuerdos institucionales para la planificación y gestión territorial de los dos municipios con políticas públicas inclusivas e incluyentes a los sectores empresariales, académicos, financieros y comunitarios que conduzcan a una visión de futuro compartida por los niveles de decisión y de actuación, regional, nacional e internacional

Prioridad 5: Construir con las iniciativas de los consulados venezolano y colombiano, y los gobiernos regionales a ambos de la frontera una agenda de gestión de integración, con propósitos de motivar, informar y formar a los diversos actores y agentes respecto al impacto que tendrá una red de emprendimiento socio-productivo en el crecimiento y desarrollo económico individual y colectivo.

\section{BIBLIOGRAFÍA}

Aguilar, M. (2001): Participación comunitaria en salud: ¿Mito o realidad?, Díaz Santos. Madrid. Aoki, M. (2007): Toward a comparative institutional analysis, MIT Press. London

Arocena, J. (2002): El Desarrollo local: un desafío contemporáneo. 2da. Edición. Universidad Católica del Uruguay y Ediciones Santillana. Montevideo.

Beer, A., y Clower, T. (2014). Mobilising leadership in cities and regions. Regional Studies, Regional Science, On-line Journal, http://rsa.tandfonline.com/doi/pdf/10.1080/21681376.2013.869428[Google Scholar]

Bass, B. (1990): "From Transactional to Transformational Leadership: Learning to Share the Vision”, Organizational Dynamics, vol. 18, n 3, pp. 19-31

Bass, B. M., y Riggio, R. E. (2006): Transformational leadership, Mahwah: Lawrence Erbaum Associates. London.

Blakely, E.J. y Bradshaw, T.K. (2002): Planning local economic development: Theory and practice. 3rd edition. Sage Publications. California. 
Bolton, R. (1992): “Place prosperity vs. people prosperity”, Urban Studies, no 29 (2), pp. 185-203

Burton, R.J., Kuczera, C. y Schwarz, G. (2008): "Exploring farmers' cultural resistance to voluntary agri-environmental schemes”, Sociologia Ruralis, vol 48, n 1, pp. 16-37.

Capello, R., Caragliu, A. y Nijkamp, P. (2009): Territorial Capital and Regional Growth: Increasing Returns in Cognitive Knowledge Use. Tinbergen Institute Discussion Paper. http://papers.tinbergen.nl/09059.pdf Downloaded: 28 September 2012

Capello, R. (2011): “Location, Regional Growth and Local Development Theories”, Aestimum, $\mathrm{n}^{\circ}$ 1, pp. 1-25.

Centro de Pensamiento para el Desarrollo (2018): Inseguridad en la Guajira, obstáculo para el desarrollo, Informe Económico Guajira 360. Guajira

Chaskin, R. J. (2008): "Resilience, community, and resilient communities: conditioning contexts and collective action”, Child Care in Practice, vol. 14, n ${ }^{\circ}$ 1, pp. 65-74.

Clingermayer, J. C. y Feijock, R. C. (2001): Institutional Constraints and Policy Choices: An Exploration of Local Governance. Albany, NY: SUNY Press. New York.

Collinge, C, Gibney, J. y Mabey, C. (2010): "Leadership and place', Policy Studies, vol. 31, n 4, pp. $\quad 367-\quad 378, \quad$ doi: 10.1080/01442871003723242 URL: http://dx.doi.org/10.1080/01442871003723242

Codhez (Comisión para los Derechos Humanos en el Estado Zulia) (2019): "Situación general de los derechos humanos en el Zulia”, Boletín de agosto 2019.

http://codhez.ong/publicaciones/boletin/

Corpozulia (2018): Caracterización Económica y social del Municipio la Guajira. Corpozulia. La Guajira. https://corporacionzulianafya.blogspot.com/

Denison, D. R., Hooijberg, R., y R.E., Quinn (1995): "Paradox and performance: Toward a theory of behavioral complexity in managerial leadership”, Organization Science, vol. 6, no 5, pp. 524-540.

Derr, C. Brooklyn, S. R. y Bournois, F. (2002): Cross-Cultural Approaches to Leadership Development. Editor. Praeger. USA.

De Santis, M. y Stough, R.R. (1999): "Fast Adjusting Urban Regions, Leadership and Regional Economic Development”, Region et Development, $\mathrm{n}^{\circ}$ 10, pp. 37-56.

Espinoza R., L. (2018): Escenarios de Integración de las Universidades de Frontera en el Proceso de Internacionalización. Doctorado en Ciencias Humanas. Línea de Investigación Relaciones Interorganizacionales y Desarrollo. Universidad del Zulia. Maracaibo, Venezuela.

Fainstein, Susan, S (2000). "New Directions in Planning Theory Urban”, Affairs Review, vol. 35, $\mathrm{n}^{\circ} 4$, pp. $451-478$.

Fairholm, G. W. (1994): Leadership and the Culture of Trust. Westport, Conn, Praeger.

Grabher, G. (1993): The Weakness of Strong Ties: The Lock-in of Regional Development in the Ruhr Area. Edit. Routledge. New York

Jessop, B. (1998): "The Rise of Governance and the Risks of Failure: The Case of Economic Development”, International Social Science Journal, n 155, pp. 29-46

Jewson, N. y MacGregor, S. (1997): Transforming Cities: New Spatial Divisions and Social Transformation. Edit. Routledge. New York.

Jorquera Beas, Daniela (2011): Gobernanza para el Desarrollo Local. Documento de Trabajo No 6. Proyecto Conocimiento y Cambio en Pobreza Rural. Rimisp, Santiago de Chile.

Heenan, D. y Bennis, W.G. (1999): Co-leaders: The Power of Great Partnerships, John Wiley. New York. 
Hofstede, G. (1993). "Cultural constraints in management theories”, The Executive, vol. 7, n 1, pp. 81-94.

Kamensky, M. (2000), Strateginen johtaminen (Strategic Management), Kauppakaari Oyj, Helsinki

Kickert, W., Klijn, E-H. y Koppenjan, J. (1997): Managing Complex Networks: Strategies for the Public Sector, Sage, London.

Malecki, E. J. (2011): “Connecting local entrepreneurial ecosystems to global innovation networks: Open innovation, double networks and knowledge integration”, International Journal of Entrepreneurship and Innovation Management, $\mathrm{n}^{\circ} 14$, pp. 36- 59.

Maskell, P. y Malmberg, A. (1999): “The competitiveness of firms and regions: 'ubiquitification' and the importance of localized learning”, European Urban and Regional Studies, vol. 6, $\mathrm{n}^{\mathrm{o}}$ 1, pp. 9-25.

Morales Zepeda, F. (2007): El Impacto de la Biotecnología en la formación de Redes Institucionales, Universidad de Barcelona, Departamento de Geografía Física y Análisis Geográfico Regional. Barcelona. https://dialnet.unirioja.es/servlet/tesis?codigo=4102

Natera Peral, A. (2005): "Nuevas estructuras y redes de gobernanza”, Revista Mexicana de Sociología, $\mathrm{n}^{\circ}$ 4, octubre-diciembre, pp. 755-791.

North, D. C. (1990): Institutions, Institutional Change and Economic Performance. Cambridge University Press. USA.

O'Neill, P., y McGuirk, P. (2002): Prosperity along Australia's eastern seaboard: Sydney and the geopolitics of urban and economic change. University Wollongong, Australian

https://ro.uow.edu.au/cgi/viewcontent.cgi?article=3144\&context=sspapers

Ostrom, E. (2005): Understanding Institutional Diversity. Princeton University Press. New Jersey - USA

Ostrom, E. (2007: "Institutional Rational Choice: an Assessment of the Institutional Analysis and Development Framework” en Sabatier, Paul A. (ed.): Theories of the Policy Process, Boulder, CO, Westview Press, pp. 21-64.

Parkinson, M. (1990): “Leadership and regeneration in Liverpool” en. Judd, y Parkinson (eds.): Leadership and urban regeneration, Newbury Park. Sage, pp.241-257.

PNUD- Colombia (2014): Anuario del proceso de paz 2012. Icaria Editorial y Universidad de Barcelona, Barcelona.

https://www.co.undp.org/content/colombia/es/home/library/crisis_prevention_and_recovery/-anuario-deprocesos-de-paz-2012.html

Rodríguez Cohard, J. C. (2009): "Los procesos de desarrollo local desde la perspectiva europea: génesis y transformación”, Semestre Económico, vol. 12, nº 24, pp. 37-55.

Rojas, R. (2012): Liderazgo distribuido para una educación de calidad. Tesis de Maestría, Universidad Andrés Bello, Santiago de Chile.

Sotarauta, M. (2016): "Regional development and regional networks; the role of regional development officers in Finland”, European Urban and Regional Studies, vol. 17, nº 4, pp. 387-400.

Stimson, R.J.; Robson, A.; Stough, R.R. y Salazar, M. (2003): "Leadership, Institutions and Regional Economic Development: A New Conceptual Framework”. Paper to Pacific

Regional Science Conference Organization, 18th Biennal Meeting, Acapulco, Mexico, July Vázquez, Barquero, A. (2005): Las nuevas fuerzas del desarrollo, Antoni Bosch, Barcelona

Vázquez Barquero, A. (2007): “Desarrollo endógeno. Teorías y políticas de desarrollo territorial”, Investigaciones Regionales, $\mathrm{n}^{\circ} 11$, pp. 183-210. 
Whittingham M, A. (2005). Aportes de la teoría y la praxis para la nueva gobernanza. Revista Reforma y Democracia. CLAD. $n^{\circ} 3$. Venezuela.

Williner, A. y Riffo Pérez, L. (2015): Estado, sociedad y liderazgo público para el desarrollo, Deocumento de trabajo CEPAL, Montevideo -Uruguay.

https://www.researchgate.net/profile/Luis_Riffo/publication/283910857_ESTADO_SOCIEDAD Y LIDERAZGO PUBLICO PARA EL DESARROLLO/links/564a137b08ae44e7a28 d91e0.pdf

Wilson, G.A. (2013): “Community resilience, policy corridors and the policy challenge”, Land Use Policy, ${ }^{\circ}$ 31, pp. 298-310. 